\title{
Postinfectious Bronchiolitis Obliterans
}

\begin{tabular}{cll|} 
Author (s) & Aslı İmran Yılmaz, Devgi Pekcan & \\
\hline $\begin{array}{c}\text { Affiliation } \\
(s)\end{array}$ & $\begin{array}{l}\text { Necmettin Erbakan University, Meram Faculty of Medicine, Department of Pediatrics, Department of } \\
\text { Pediatric Pulmonology, Konya, Turkey }\end{array}$ \\
Article & $\begin{array}{l}\text { Article Type: Invited Review } \\
\text { Anformation }\end{array}$ & $\begin{array}{l}\text { Received: } 10.10 .2021 \\
\text { Accepted: } 14.12 .2021 \\
\text { Available Online: } 31.12 .2021\end{array}$ \\
\hline
\end{tabular}

\section{Abstract}

Childhood bronchiolitis obliterans (BO) is an uncommon complication that is characterized clinically by persistent and continuous obstructive respiratory symptoms, and has been described secondary to various etiologic factors, including drugs, exposure to toxic fumes, allergic reactions, collagen vascular disease or infections. BO occurs most commonly in children after an episode of acute bronchiolitis and is considered a long-term sequela of viral infection.

Postinfectious Bronchiolitis Obliterans (PIBO) is characterized by persistent airway obstruction with functional and radiological evidence of small airway involvement that is in general unresponsive to bronchodilator treatment.

Although the condition is relatively rare, and its exact incidence is unknown, it is important to keep it in mind. PIBO is complication of lower respiratory tract epithelial injury, and is often misdiagnosed, delaying recognition and potential treatment. A PIBO diagnosis is usually based on a few factors, including a good medical history, positive clinical findings, and lung function test and imaging results, although biopsy and histopathology remain as the optimum diagnostic approach. There have to date been few studies proposing treatments for the condition, and no accepted protocol exists in literature. There is usually a fixed airway obstruction in PIBO. Various treatment approaches have been extrapolated from studies of post bone marrow transplantations and lung transplant BO. The clinical course is variable, and good supportive therapy is essential, with anti-inflammatory therapy often being employed.

Keywords: Bronchiolitis obliterans, postinfectious bronchiolitis obliterans, mosaic pattern

Correspondence: Aslı İmran Yılmaz,Necmettin Erbakan University, Meram Faculty of Medicine, Department of Pediatrics, Department of Pediatric Pulmonology, Yunus Emre mah. No:281, 42090, Meram, Konya, Turkey

E-mail: asli-turkut@hotmail.com 


\section{Introduction}

Bronchiolitis obliterans (BO) is a rare obstructive lung disease that was first described by Lange in $1901 .^{1}$ It is an irreversible chronic lung disease that is characterized by subepithelial inflammation and a fibrotic narrowing of the small airways due to various etiologic and triggering factors. ${ }^{2,3}$ To date, three main $\mathrm{BO}$ categories have been encountered: (i) postinfectious $\mathrm{BO}$ (PIBO), (ii) posthematopoietic stem cell transplantation (HSCT) BO and (iii) post-lung transplantation (LT) BO. Cases in all three categories present with irreversible airway obstructions in the small airways, and respiratory symptoms secondary to this, with the most common cause being infection. PIBO is often seen in early childhood and is an obstructive lung disease that is generally irresponsive to bronchodilator treatment that is characterized by a fibrotic narrowing of the bronchioles secondary to severe lower respiratory tract infection. ${ }^{4-7}$ Other rare causes in the $\mathrm{BO}$ etiology are connective tissue disease, exposure to toxic fumes and gastroesophageal reflux.,9

\section{Pathogenesis}

The pathogenesis of bronchiolitis obliterans is still unclear as the causative organisms are numerous. $T$ cells are known to play a key role in the development of various inflammatory diseases. ${ }^{10}$

In BAL studies of matrix metalloproteinases (MMP), reactive oxygen species and defensins, neutrophils have been shown to play a role in the pathogenesis of BO primarily after lung transplantations. Damaged epithelial cells following post lung transplantation have been suggested to cause an accumulation of inflammatory cells, including neutrophils, through the release of IL-8 and other proinflammatory cytokines. These neutrophils are considered to cause an increase in MMP, defensins and reactive oxygen species, thus leading to structural disorders of the matrix, collagen accumulation, fibroblast proliferation, and finally, peribronchial fibrosis. ${ }^{11}$

Recently, a Th17 cell mediated autoimmunity was detected against the type- $V$ collagen that plays role in tissue remodeling in patients with lung transplant. ${ }^{12}$ In a BO animal model, IL-17 expression was found to increase and peripheral Tregs to decrease in the allograft after LT. ${ }^{13}$ Considering the induction of IL- 8 secretion by IL-17, Th17 cells may be responsible for the neutrophilia observed in the BAL of patients with BO. PIBO, on the other hand, is characterized by a constrictive $\mathrm{BO}$ pattern and inflammation to a varying degree, along with airway obstruction.

In summary, epithelial damage occurs as a result of lower respiratory tract infections by viruses or microorganisms such as mycoplasma. Epithelial cells secrete IL-8 and other proinflammatory mediators that gather neutrophils and other inflammatory cells into the small airways. Subsequently, MMP, fibrotic cytokines and mediators are secreted by these cells, and matrix damage, collagen accumulation, fibroblast proliferation, and finally, peribronchial fibrosis occur. CD8 + T cells play a dominant role in epithelial damage and chronic inflammation following a viral infection. Th17 cells play role in tissue remodeling, while IL-17 induces the IL-8 release associated with airway neutrophilia. The development of obliteration in $\mathrm{BO}$ is detailed in Figure 1.

\section{Highlights}

- Bronchiolitis obliterans is a rare obstructive chronic lung disease.

The common features of Bronchiolitis CT in particular plays a central role in the diagnosis of PIBO, identifying such malies as patchy ground glass perfusion and unilateral hyperlucent lung.

\section{Definition}

The common features of Bronchiolitis Obliterans are tachypnea, wheezing and hypoxemia continuing for at least for 6 weeks following a causative event. ${ }^{14}$ Diagnoses are confirmed from persistent symptoms irresponsive to bronchodilator application, computed tomography findings and the exclusion of other diseases. ${ }^{15}$

\section{Epidemiology}

Postinfectious Bronchiolitis Obliterans (PIBO) is a rare disease, the incidence of which is currently unknown since a national and international database has yet to be established. The incidence may be even higher than expected, since most mild cases remain undiagnosed. While estimating the prevalence of PIBO is difficult, in a study of 3,141 autopsy and lung biopsy reports, $\mathrm{BO}$ was identified in $0.6 \%$, and most were described as PIBO ${ }^{16} \mathrm{PIBO}$ is encountered more frequently among certain populations, including Native Americans and Native Koreans, which suggests that genetic factors may play role in its etiology.,17 HLADQB1 * 0302 - an antigen with a high prevalence among Native Americans was found to be increased in children with $\mathrm{BO}$ in a previous study.

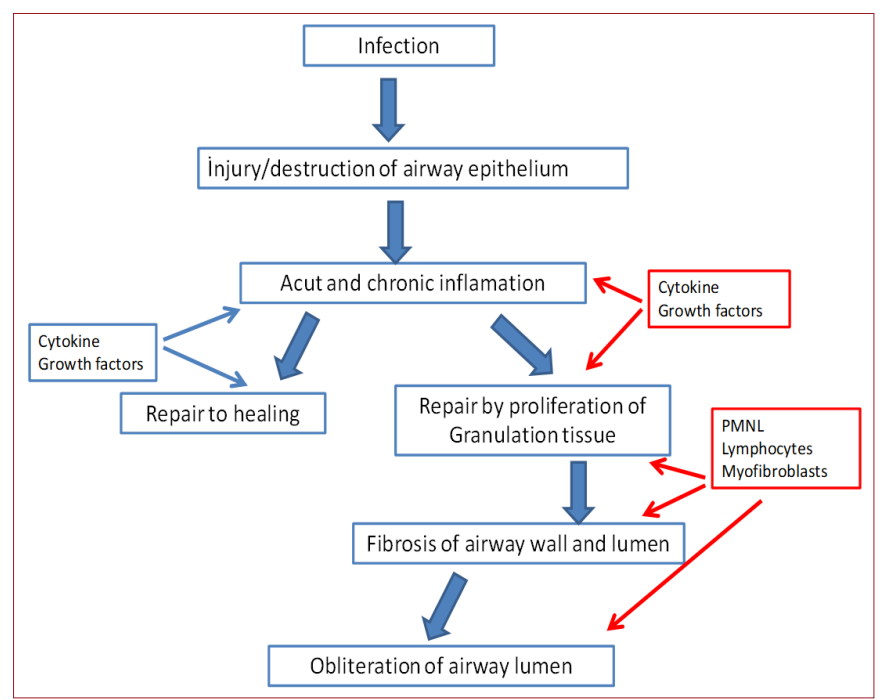

Figure 1. Histopathology in Bronchiolitis Obliterans 
PIBO is most associated with adenovirus infections $(3,7$, 11 and 21 serotypes), and has been reported secondary to influenza, parainfluenza, measles, chickenpox and Mycoplasma pneumoniae. Li et al., in their study conducted in China, reported adenovirus to be the most common cause in the 42 PIBO diagnoses of children over a five-year period. ${ }^{18}$ Colom et al. diagnosed adenovirus in $71 \%$ of their patients with $\mathrm{PIBO},{ }^{4}$ although various respiratory viruses or bacteria, including respiratory syncytial virus, influenza, Mycoplasma pneumoniae, type B Streptococcus, Legionella pneumophilia and Bordetella pertussis have been shown to lead to the development of PIBO. ${ }^{19,20}$

Respiratory signs and symptoms of acute viral bronchiolitis resolve after a few days, and so BO should be considered in children with acute lower respiratory tract infections with continued wheezing, tachypnea and the need for oxygen support for at least 2 months. Advanced diagnoses are necessary in such cases. ${ }^{1,9}$ Adenovirus infection has been found to be an independent risk factor for the development of PIBO in children below 3 years of age with a requirement for mechanical ventilation. ${ }^{4}$ PIBO is particularly common in children below 1 year of age, although age does not seem to be a risk factor for PIBO. ${ }^{4,21,22}$

Children with PIBO are heterogeneous in terms of the causative organisms and the age of onset. Pediatric pulmonologists have been able to determine the cause and initiation time from retrospective observations at the time of diagnosis. In a study with a 3.5-year follow-up, $22.6 \%$ of the cases were reported to be in remission, $67.7 \%$ were reported to have continuing respiratory symptoms and mortality was reported in $9.7 \%{ }^{22}$

\section{Histopathology}

The fibrotic changes in the small airways associated with BO can be divided into two types: proliferative bronchiolitis; obstructive or constrictive bronchiolitis, depending on their histologic features, the second of which is more common. ${ }^{23}$ Constrictive bronchiolitis develops due to submucosal fibrosis, while proliferative bronchiolitis develops when intraluminal polyps caused by inflammatory granulation tissues obstruct the airways. ${ }^{24}$ The mechanism of the development of obliteration in $\mathrm{BO}$ is detailed in Figure 1.

Lung biopsy is accepted as the optimum approach to the diagnosis of BO. Typically, biopsies reveal a progressive inflammatory response with tissue remodeling, fibrosis of the small airways and airway obstruction elements, ${ }^{25}$ although such biopsies may be subject to sampling errors, since airway obstructions are distributed heterogeneously in the lung parenchyma and the level of chronic inflammation varies from patient to patient.

\section{DIAGNOSIS}

\section{Clinical Picture}

PIBO is diagnosed from the clinical criteria that define the symptoms, such as tachypnea, cough, wheezing, exercise intolerance and hypoxemia, continuing for at least 6 weeks following severe bronchiolitis or pneumonia with respiratory failure.

Differentiating between PIBO and ordinary bronchiolitis or viral pneumonia can be challenging, and may delay diagnosis and possible treatment, and such delays may result in deepening the severity of respiratory tract infections and even death from respiratory failure over $1-2$ years. ${ }^{15-26}$

At the time of diagnosis, the level of respiratory tract disease may have advanced and irreversible fibrotic changes and airway obstructions may have occurred, making treatment even more difficult and decreasing the rate of success. Physical examination does not lead in a previously health child in the diagnosis of PIBO. There are nonspecific signs which point out PIBO such as crepitant rales, wheezing and hyperinflation on physical examination. A definitive diagnosis necessitates histopathological verification and so clinical and imaging criteria, pathological agent descriptions and the exclusion of other forms of chronic lung disease should be carried out as a priority. The diagnostic criteria for PIBO are given in Table 1. ${ }^{27}$

A scoring system to increase reliability in positive cases was developed and validated in a study carried out to establish the diagnostic criteria of the disease, and to determine the accuracy of the criteria in the evaluation of pediatric patients with PIBO - a chronic lung disease. The defined criteria were as follows: Typical clinical record in a previously healthy child with a severe bronchiolitis episode lasting for more than 60 days; presence of chronic hypoxemia (sat. $\mathrm{O}_{2}<92 \%$ ): 4 points; history of adenovirus infection: 3 points; and mosaic pattern on CT: 4 points. Scores of $\geq 7$ predict a diagnosis of PIBO with a high accuracy (specificity $100 \%$, sensitivity $67 \%$ ), although scores of $<7$ certainly do not exclude a diagnosis of $\mathrm{BO}$. The specificity criteria of PIBO are presented in Table $2 .^{22}$

2. Persistent airway obstruction symptoms and signs ( $\geq 6$ weeks) or recurrent airway obstruction symptoms and signs in a mild form.

3. Sing of obstructions: FEV1 /FVC $<0,8$ or FEV1 percent predicted $<\% 80$.

4. Irreversible airway obstruction demonstrated by lung function test; absent BDT but positive BDR in some patient.

5. CT (inspiration/expiration): mosaic perfusion, air trapping, and/or bronchiectasis

6. Exclusion of other chronic lung disease (asthma, BPD, chronic aspiration, PCD, cystic fibrosis, immun deficiency).

7. Postinfectious bronchiolitis obliterans is clinically diagnosed when all of the above criteria are met.

FEV1: Functional expiratory volüme, FVC: Forced Vital Capacity, BDT: Bronchodilator Therapy, BDR: Bronchodilator Response, CT: Computed Tomography, BPD: Bronchopulmonary Dysplasia, PCD: Primary Ciliary Dyskinesia 
Table 2

BO score, clinical X-Ray score for diagnosis PIBO

\begin{tabular}{lcc}
\hline Predictor variable & \multicolumn{2}{c}{ Value } \\
\cline { 2 - 3 } & Present & Absent \\
\hline Typical clinical record & 4 & 0 \\
Adenovirus history & 3 & 0 \\
Mosaic pattern in HRCT & 4 & 0 \\
Score range 0-11 & & \\
\hline A score $>$ 7 predict diagnosis PIBO & & \\
\hline
\end{tabular}

One of the most severe forms of PIBO caused by adenoviruses is Swyer-James Syndrome (SJS), which is defined as the unilateral hyperlucency of a single lobe or the entire lung secondary to pulmonary hypoperfusion, with a decrease in the vascular plexus or volume of the affected lung or lobe. SJS is functionally characterized by a decrease in volume during inspiration and air trapping due to bronchiolar obstructions during expiration. Given the rarity of the disease, understanding the general clinical picture of SJS is important in excluding other diseases associated with bronchiolitis for a differential diagnosis. The physiopathology of SJS includes inflammation of the bronchial walls and fibrosis of the interalveolar septa, resulting in decreased ventilation and perfusion, and vasoconstriction. Obliteration of the pulmonary capillary network decreases the flow of blood into the pulmonary artery segments and triggers arterial hypoplasia. ${ }^{28,29}$

\section{Radiology}

Among the available imaging techniques, CT in particular plays a central role in the diagnosis of PIBO, identifying such anomalies as patchy ground glass opacities, air retention, bronchial wall thickening, bronchiectasis, mosaic perfusion and unilateral hyperlucent lung..$^{30}$ The most common findings - mosaic attenuation and ground glass appearance - are essential for diagnosis. Some sample CT images of BO are presented in Figure 2 and Figure 3. The two main mechanisms behind the development of mosaic attenuation are alveolar hyperinflation and hypoxic vasoconstriction. ${ }^{31}$ Hypoxic vasoconstriction causes a redistribution of blood flow to the "healthy" lung. When the bronchial disease is extensive, a greater volume of blood is redistributed to the smaller volume healthy lung, finally becoming more condensed, and a ground glass appearance develops. Leung et al. reported the sensitivity, specificity and accuracy of CT in cases of air trapping syndrome to be $91 \%, 80 \%$ and $86 \%$, respectively. ${ }^{32}$ Obtaining a CT image during the expiratory phase would lead to this important feature, which occurs during the inspiratory phase, being overlooked, and so it is important in diagnoses of air trapping in less severe cases. ${ }^{33}$ Obtaining scans from both respiratory phases may be challenging in pediatric patients with limited cooperation; and so more attention should be paid to the evaluation of ground glass opacities. Another role of CT in PIBO is as a marker of disease severity. Correlations have been observed between CT measurements of disease severity and lung function measurements in $\mathrm{BO}$ in the presence of varying etiologies. ${ }^{34}$ Ventilation-perfusion (V/Q) defects in scintigraphic imaging in only PIBO patients have been reported in some studies. ${ }^{35}$

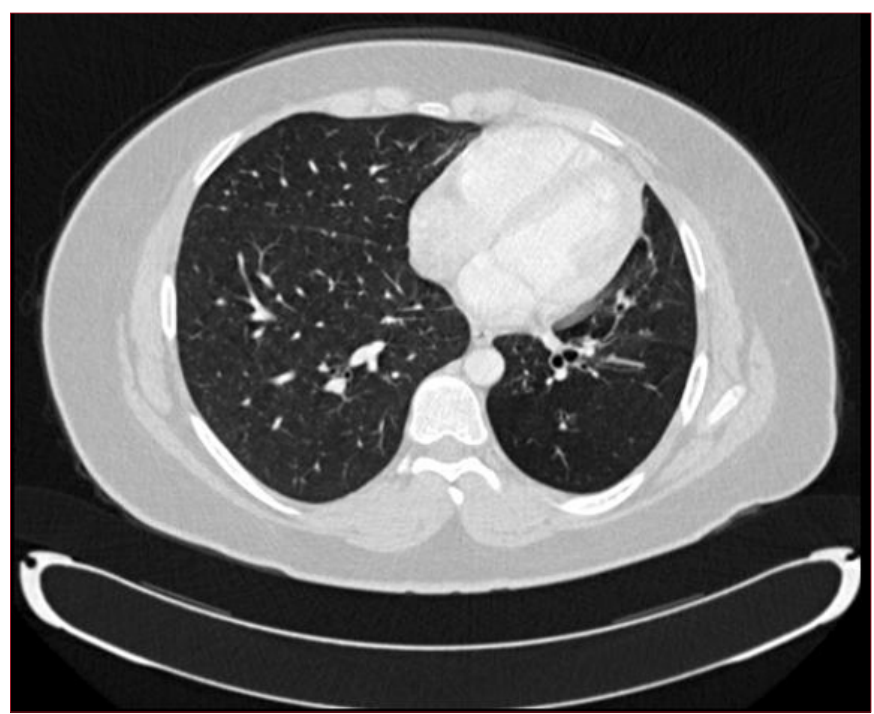

Figure 2. Swyer-James (Macleod Syndrome): radiographic hyperlucent appearance of a left pulmonary lobe.

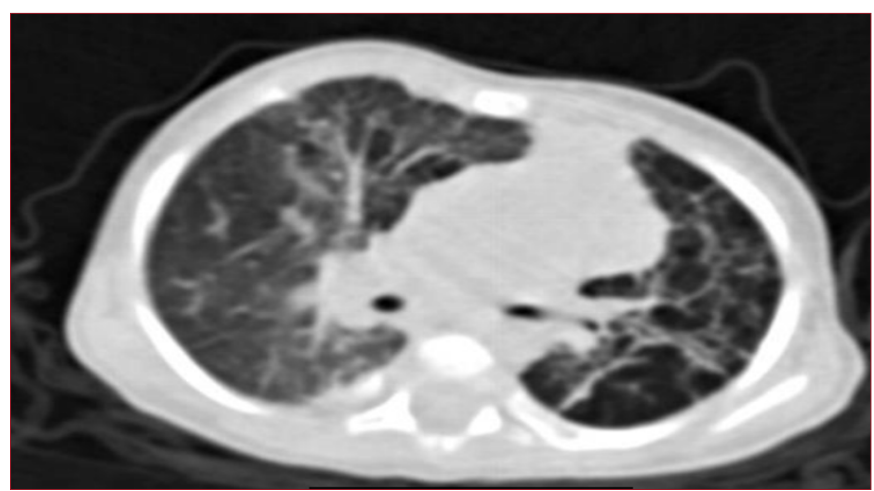

Figure 3. Swyer-James (Macleod Syndrome), CT demonstrate longstanding hyperlucency of the right lower lobe

Bo-Qia Xie et al. identified two further patterns, including incompatible perfusion pattern and incompatible ventilation pattern. ${ }^{36}$ Airway inflammation is thought to lead to hypoxic vasoconstriction in the acute phase, and this inflammatory process is thus accepted as affecting the neighboring vessels, and to cause vascular remodeling in the following chronic phase. ${ }^{37}$ Perfusion disorder may thus be less severe than ventilation disorder in the early phases of PIBO, and so an incompatible perfusion pattern may be seen on a V/Q scan. An incompatible perfusion pattern, on the other hand, may be a sign of early phase PIBO, and the incompatible ventilation pattern follows this. ${ }^{36}$

\section{Pulmonary Function Tests (PFT)}

Lung function tests are manifested as typical models in patients with PIBO. Pulmonary function tests are generally used to document an obstructive disorder, although the results of such tests may be normal in the early phases. Spirometry shows an irreversible of stable obstructive flow volume curve with a decreased forced expiratory volume (FEV1), and a decreased Tiffeneau index (FEV1/FVC) and end-expiration (FEF25). The body plethysmography shows hyperinflation and a residual volume (RV) with increased air trapping and an increased functional residual capacity (FRV). ${ }^{17}$ Typically, response to bronchodilation is either low or lacking. ${ }^{38}$ Patients with PIBO tend to experience milder disease forms than those with BOS following bone marrow transplantations. 
Patients with PIBO have a common marked respiratory function disorder pattern that is characterized by marked airway obstruction, increased RV and specific airway resistance.

Mattiello et al. reported that airway obstructions varied between intermediate to very severe in children and adults with PIBO, noting also marked airway obstructions with air trapping. ${ }^{39}$

Teper et al. from Argentina reported that the respiratory functional disorder associated with PIBO developed in the early phases of the disease. ${ }^{40} \mathrm{Kim}$ et al. identified severe and fixed airway obstructions in the pulmonary function tests of 14 children out of 31 with PIBO in the United States and South Korea. ${ }^{17}$ Cazzato et al. found a yearly $1 \%$ decrease in the FEV1, FEV1 / FVC and FEF25-75 values of 14 children in the long-term followup of pulmonary function tests. ${ }^{38}$

Castro-Rodriguez et al. identified a peripheral airway obstruction in 18 preschool children with PIBO in Chili using an impulse oscillometer technique. ${ }^{41}$ In Brazil, Mattiello et al., after evaluating the functional capacity of 20 children during cardiopulmonary exercise, compared their results with the PFT results. The authors found decreased oxygen consumption to be positively correlated with FVC, FEV1 and FRC in children, ${ }^{42}$ and reported that the CT findings early in life in a group of 21 children with PIBO predicted severely impaired lung function after 10 years. ${ }^{43}$ This impairment which is probably attributable to the huge chronic damage in the intermediate and small airways, characterized by increased RV and specific airway resistance (sRaw), and decreased expiratory air flow. A combination of spirometry and plethysmography measurements may be more beneficial for the evaluation of functional damage, and for the follow-up of such patients when compared to use of only one technique alone..$^{44}$

Mattielo et al. reported decreased FVC in PIBO, and a total lung capacity (TLC), RV and RV/TLC of over $80 \%$, representing a significant increase. These data, obtained from plethysmography, confirmed the obstructive nature of PIBO. The authors also reported a positive correlation between RV/TLC and FEV1 and demonstrated that the decrease in FEF25-75\% was in parallel with the severity of the airway obstruction. Although FEV1/ FVC and FEV1 are the most used spirometry parameters for the determination of airway obstructions, this parameter was an early predictor of disease severity since it shows a greater decrease when compared to FEF25-75, FEV1\% or FEV1. RV, TLC and RV/TLC tend to increase in such patients as a result of the decrease in the elastic recoil of the lung. ${ }^{42}$

The FEV1 and FEV1/FVC and FEF25-75 of patients with PIBO should be carefully monitored. ${ }^{44}$ Both the American Thorax Society (ATS) and the European Respiratory Society (ERS) recommend the determination of lung volumes in patients with obstructive lung diseases such as PIBO to allow a better understanding of the underlying respiratory disorder. ${ }^{45,46}$

Anatomical and functional changes in PIBO may lead to a progressive loss of power/ durability in the respiratory muscles, which in turn effects exercise tolerance negatively and may decrease daily life activities. A cardiopulmonary exercise test (CPET) and a 6-minute walking test may be more sensitive in the detection of early involvement in respiratory diseases the FEV1 measured by spirometry. Mattiello R et al. identified a decrease in exercise capacity in children and adolescents with PIBO. ${ }^{44}$

Recently, sensitive lung function indices have aided in the early diagnosis of small airway disorders in PIBO. Multiple breath washout (MBW) is an appropriate and sufficiently sensitive method for the detection of early small airway disorders in the presence of chronic lung disease in children and adults. Other studies have shown the lung clearance index ( $\mathrm{LCl}$ ) to be impaired in most patients with cystic fibrosis, despite the spirometry indices being normal. $\mathrm{LCl}$ measured by $\mathrm{MBW}$ can be helpful in the diagnosis in PIBO. $\mathrm{LCl}$ results were found to be correlated with CT findings in Kim et al.'s study of 20 babies diagnosed with PIBO who underwent pulmonary function tests, MBW and chest CT. LCl can thus be considered an appropriate and complementary tool for the evaluation of children with PIBO..$^{47,48} \mathrm{It}$ offers a further advantage over Forced Oscillation Technique (FOT) spirometry in the pediatric population in requiring no respiratory maneuvers due to the small amplitude pressure oscillations added to the normal respiration. There have to date been no studies investigating the use of FOT in PIBO, although such may be of interest, and would facilitate pulmonary function studies ${ }^{49}$ In contrast to spirometry, which requires deep inspiration, the FOT requires minimal cooperation and does not alter the airway smooth muscle tonus.

Jang $Y Y$ et al. reported a significant increase in serum YKL-40 levels in children presenting with exacerbations of PIBO, and these increased YKL-40 levels were found to be positively correlated with disease severity prior to PIBO. The measurement of serum YKL-40 levels was thus suggested to be helpful in differentiating between exacerbation in PIBO and acute bronchiolitis in small children, and it was concluded that YKL-40 could play a role in the pathogenesis of PIBO. ${ }^{50}$

Giubergia $V$ et al., in their study evaluating the distribution of MBL2 polymorphism in children with PIBO, identified significantly more children carrying $\mathrm{MBBL}$ genetic variants in the PIBO group when compared to healthy controls, and more patients in the PIBO $\mathrm{iMBL}$ group required intensive care and mechanical ventilation. ${ }^{51}$

\section{BAL}

Cellular infiltrations of the lungs in children with PIBO involve CD3 + T cells, in which the CD8 + T cell subtype is dominant. Koh et al. identified increased CD8 + T cells and a decreased ratio of CD4 / CD8 in BAL and biopsy samples taken from children with $\mathrm{BO}$ and with a history of measles pneumonia during an outbreak in 2000-2001. The dominant role of CD8 + T cells in the development of BO following a viral infection was described in this study.

The bronchoalveolar lavage (BAL) of children with PIBO is neutrophil dominant and a significant increase in IL-8 is seen, with the degree of neutrophil increase in BAL being correlated with the $\mathrm{BO}$ stage. ${ }^{10}$ 


\section{Biopsy}

Biopsy is accepted as the optimum approach to diagnosis, although the National Institute of Health (NIH) came up with new criteria for the diagnosis and scoring of the severity of chronic Graft-versus-host disease (GVHD) of the lungs, since biopsy is invasive and is associated with a risk of bleeding and other complications. The criteria for a clinical diagnosis of BOS after HSCT were defined as FEV1/FVC $<0.7$, FEV $1<75 \%$ pred., $>10 \%$ decrease in less than 2 years, and an absence of infection or air trapping in a CT or pulmonary function test. Similar follow-ups should be carried out for PIBO. ${ }^{52}$

\section{Treatment}

Standard treatment options are yet to be determined for $\mathrm{PIBO}$, as it is a rare, chronic, irreversible and obstructive lung disease with no accepted protocol, and different centers follow different strategies. Most of the current knowledge of PIBO has been extrapolated from studies of patients who developed BOS following bone marrow or lung transplantations. ${ }^{53}$

Therapeutic decisions were empirically performed in the beginning, since PIBO is a rare disease in which there is little opportunity for randomized clinical experiments focusing on the treatment of the disease. The clinical course is variable, and supportive treatment is the main priority, although anti-inflammatory treatments are also frequently applied. The current BO treatments are details in Table 3. ${ }^{54,55}$

\section{Table 3}

Treatment of PIBO

\begin{tabular}{|c|c|}
\hline Anti-inflammatory therapy & Supportive treatment \\
\hline - Systemic steroid & - Oxygen support \\
\hline - Azithromycin & - Nutritional support \\
\hline $\begin{array}{l}\text { - Combination therapy: FAM } \\
\text { (fluticasone/azithromycin/ } \\
\text { montelukast) }\end{array}$ & $\begin{array}{l}\text { - Vaccination (influenza/ } \\
\text { pneumococcus) }\end{array}$ \\
\hline - Immunoglobulin therapy & - Avoiding cigarette smoke \\
\hline $\begin{array}{l}\text { - Steroid sparing } \\
\text { antiinflammatory agents }\end{array}$ & $\begin{array}{l}\text { - Airway clearance if there is } \\
\text { bronchiectasis }\end{array}$ \\
\hline \multirow[t]{2}{*}{ - Anti-TNF } & $\begin{array}{l}\text { - Inhaler bronchodilator if } \\
\text { response }\end{array}$ \\
\hline & $\begin{array}{l}\text { - Exercise therapy/pulmonary } \\
\text { rehabilitation }\end{array}$ \\
\hline
\end{tabular}

In general, PIBO treatments should be planned to include a combination of optimal supportive therapy and anti-inflammatory treatment to prevent lymphocyte proliferation and activation, since inflammation plays an important role in the pathogenesis of PIBO..$^{56} \mathrm{An}$ appropriate drug protocol may include: 1) Oral/inhaled corticosteroids and other anti-inflammatory treatments; 2) hydroxychloroquine, for the treatment of severe or longlasting obstructions; and high dose methylprednisolone pulses; 3) Short-acting and long-acting bronchodilators or anticholinergic agents; and 4) oral or intravenous antibiotics. ${ }^{57}$

\section{Inhalers and systemic steroids:}

Systemic steroids should be administered in the early phases of the disease, prior to the development of fibrosis, although the small airways might already be obstructed by fibrosis when the PIBO diagnosis was made. Since the duration of inflammation following the development of PIBO is unknown, it is hard to know when the systemic steroid treatment should begin and end. ${ }^{8}$ The preferred approach is a pulse steroid treatment with intravenous methylprednisolone for 3 consecutive days in a dose of $10-30 \mathrm{mg} / \mathrm{kg}$. Consensus is that the treatment should be repeated every 3-6 months, as is the case with pediatric interstitial lung disease. Yalcin et al. gave prednisolone in a dose of $1 \mathrm{mg} / \mathrm{kg} /$ day in their patients as the initial dose. Treatment lasted between 6 and 27 months, and the steroid dose was decreased gradually 3 months after the initiation of treatment. ${ }^{58}$

\section{Macrolides}

The adverse effects of long-term systemic glucocorticoid and inhaled corticosteroid administration has led investigators to seek an alternative treatment for $\mathrm{BO} \cdot 59,60$ The anti-inflammatory and immunomodulator effects of macrolides have recently been noted, leading to their use in the treatment of $\mathrm{BO}$ following transplantation. Azithromycin is a macrolide-group antibiotic that has proven to be effective in the treatment of diffuse pan bronchiolitis and cystic fibrosis in prospective, doubleblind and placebo-controlled studies. ${ }^{61}$ Macrolide antibiotics are known to show immune modifying effects in addition to their antimicrobial roles, while Azithromycin was shown to improve FEV1 and to decrease mortality in patients with $\mathrm{BO}$ syndrome following lung transplantation in an extensive study in 2014 and a large scale randomized clinical study in 2015. ${ }^{62-64}$ The recommendation for the use of macrolides in the treatment of BO after lung transplantation is recommended for Grade IA and Grade $2 \mathrm{C}$ stages of allograft rejection. ${ }^{65}$

\section{Leukotriene Receptor Antagonists}

The effectivity of leukotriene receptor antagonists is linked to their ability to inhibit airway inflammation. ${ }^{66}$ Montelukast provided a high treatment efficacy in $\mathrm{BO}$ patients after transplantation. ${ }^{67} \mathrm{~A}$ recent study reported that a combination treatment including budesonide, montelukast and azithromycin improved pulmonary function and respiratory symptoms in children with PIBO aged $<5$ years. Concurring with this finding, Williams et al. reported that fluticasone, azithromycin and montelukast, alongside pulse steroid treatment, could halt the decrease in pulmonary functions in newly developed $\mathrm{BO}$, and could lead to a decrease in systemic steroid exposure in most patients. ${ }^{68,69}$ In another study, concurring with the studies mentioned above, use of budesonide, azithromycin and montelukast in combination for at least 3 months was said to improve respiratory function and respiratory symptoms in children with PIBO. ${ }^{70}$

Recently, treatment strategies have become more personalized. Systemic steroids or inhaled corticosteroids are recommended in all patients, although the route of steroid application should be chosen empirically, based on the severity of the case. In theory, no bronchodilator 
response is expected in children with permanent airway obstructions such as in $\mathrm{PIBO}$, however a positive bronchodilator response can be seen ranging from $10 \%$ to $42.9 \%$. Inhaled bronchodilators (short-acting ß-2) are recommended for all patients with pulmonary exacerbations and who are clinically responsive. ${ }^{71-73}$

Oxygen support may also be used in addition to drug treatment, especially in the first few years of the disease, and clinical improvement can permit the cessation of supplementary oxygen completely in most cases. The requirement of supplementary oxygen at night is a source of concern, although significant desaturation is experienced only severe cases during sleep. ${ }^{74}$

Nathan et al. reported increased pulmonary pressure in $42.3 \%$ of patients $(\mathrm{PH})$ with $\mathrm{BO}$ following LT. ${ }^{75}$ Pate et al. reported that three out of four patients $(75 \%)$ with BO were diagnosed with $\mathrm{PH} 91$ days after HSCT. ${ }^{76}$ Chen et al. reported that two out of the eight children with $\mathrm{PIBO}$ in their study had $\mathrm{PH}(25 \%)$, leading them to add sildenafil to the treatment protocol. Considering the association between $\mathrm{BO}$ and $\mathrm{PH}$, patients with $\mathrm{PIBO}$ should be screened regularly for $\mathrm{PH}$. Furthermore, since hypoxemia is present in both $\mathrm{BO}$ and $\mathrm{PH}$, hypoxemia in patients with $\mathrm{BO}$ is typically due to worsening $\mathrm{PH}$, and $\mathrm{PH}$ also worsens hypoxemia.

GER has been reported to contribute significantly to the deterioration of respiratory function in patients with $\mathrm{BO}$, making it mandatory to treat the condition when diagnosed.

Other immunosuppressive agents, including methotrexate, azathioprine, cyclophosphamide, thalidomide, imatinib and etanercept, have been tested on patients with BOS following lung transplantation or HSCT. Although most studies are retrospective, case reports or case-controlled studies, the results are not promising, and no reports are found associated with the use of these drugs in children with PIBO. ${ }^{77-81}$ Recent case studies have reported that the administration of intravenous immunoglobulin alongside pulse steroid treatment or methylprednisolone in a dose of $1 \mathrm{mg} / \mathrm{kg}$ as an effective treatment. ${ }^{82,83}$ Lung transplantation remains as the final option in children with BO following LT or HSCT that progresses to end-stage lung disease. In one hospital-based study, two of the 31 cases with diffuse lung disease other than cystic fibrosis and pulmonary vascular disease who underwent lung transplantations were patients with PIBO ${ }^{84}$ Accordingly, LT should be considered in patients with PIBO in whom the disease has progressed to end-stage lung disease.

\section{Clinical progress}

Most patients require oxygen support for an average of 5 months following admission to hospital. Oxygen saturation improves slowly over several years, and only a few patients need additional oxygen support past the age of 10 years. Child patients require readmissions to hospital, although the frequency of admissions decreases over the years, ${ }^{21}$ with such readmissions being required mainly due to respiratory tract infections that require treatment with antibiotics, bronchodilators and physiotherapy. ${ }^{85}$
Perfusion defects that are present at the outset of the disease continue in most patients but may resolve occasionally. The clinical improvements seen in such patients may be due to pulmonary enlargement, rather than being a sign of regression of a small airway pathology. ${ }^{86}$

Conflict of Interest Statement: The authors have no conflicts of interest to declare.

Financial Disclosure: The authors declared that this study has received no financial support.

Peer-review: Externally peer-reviewed.

\section{References}

1. Jerkic SP, Brinkmann F, Calder A, et al. Postinfectious Bronchiolitis Obliterans in Children: Diagnostic Workup and Therapeutic Options: A Workshop Report. Can Respir J. 2020;2020:5852827 [CrossRef]

2. Barker AF, Bergeron A, Rom WN, Hertz MI. Obliterative bronchiolitis. N Engl J Med. 2014;370:1820-1828. [CrossRef]

3. Yu J. Postinfectious bronchiolitis obliterans in children: lessons from bronchiolitis obliterans after lung transplantation and hematopoietic stem cell transplantation. Korean J Pediatr. 2015;58:459-465. [CrossRef]

4. Colom AJ, Teper AM, Vollmer WM, Diette GB. Risk factors for the development of bronchiolitis obliterans in children with bronchiolitis. Thorax. 2006;61:503-506. [CrossRef]

5. Champs NS, Lasmar LM, Camargos PA, Marguet C, Fischer GB, Mocelin HT. Post-infectious bronchiolitis obliterans in children. $J$ Pediatr (Rio J). 2011;87:187-198. [CrossRef]

6. Hogg JC, Paré PD, Hackett TL. The Contribution of Small Airway Obstruction to the Pathogenesis of Chronic Obstructive Pulmonary Disease [published correction appears in Physiol Rev. 2018 Jul 1;98(3):1909]. Physiol Rev. 2017;97:529-552. [CrossRef]

7. Lino CA, Batista AK, Soares MA, et al. Bronchiolitis obliterans: clinical and radiological profile of children followed-up in a reference outpatient clinic. Rev Paul Pediatr. 2013;31:10-16. [CrossRef]

8. Moonnumakal SP, Fan LL. Bronchiolitis obliterans in children. Curr Opin Pediatr. 2008;20:272-278. [CrossRef]

9. Murtagh P, Giubergia V, Viale D, Bauer G, Pena HG. Lower respiratory infections by adenovirus in children. Clinical features and risk factors for bronchiolitis obliterans and mortality. Pediatr Pulmonol. 2009;44:450-456. [CrossRef]

10. Koh YY, Jung DE, Koh JY, Kim JY, Yoo Y, Kim CK. Bronchoalveolar cellularity and interleukin-8 levels in measles bronchiolitis obliterans. Chest. 2007;131:1454-1460. [CrossRef]

11. Kennedy VE, Todd JL, Palmer SM. Bronchoalveolar lavage as a tool to predict, diagnose and understand bronchiolitis obliterans syndrome. Am J Transplant. 2013;13:552-561. [CrossRef]

12. Burlingham WJ, Love RB, Jankowska-Gan E, et al. IL-17dependent cellular immunity to collagen type $\mathrm{V}$ predisposes to obliterative bronchiolitis in human lung transplants. J Clin Invest. 2007;117:3498-3506. [CrossRef]

13. Nakagiri T, Inoue M, Morii E, et al. Local IL-17 production and a decrease in peripheral blood regulatory $T$ cells in an animal model of bronchiolitis obliterans. Transplantation. 2010;89:1312-1319. [CrossRef]

14. Kurland G, Michelson P. Bronchiolitis obliterans in children. Pediatr Pulmonol. 2005;39:193-208. [CrossRef]

15. Champs NS, Lasmar LM, Camargos PA, Marguet C, Fischer GB, Mocelin HT. Post-infectious bronchiolitis obliterans in children. J Pediatr (Rio J). 2011;87:187-198. [CrossRef]

16. Hardy KA, Schidlow DV, Zaeri N. Obliterative bronchiolitis in children. Chest. 1988;93:460-466. [CrossRef]

17. Kim CK, Kim SW, Kim JS, et al. Bronchiolitis obliterans in the 1990s in Korea and the United States. Chest. 2001;120:11011106. [CrossRef]

18. Li YN, Liu L, Qiao HM, Cheng H, Cheng HJ. Post-infectious bronchiolitis obliterans in children: a review of 42 cases. BMC Pediatr. 2014;14:238. [CrossRef] 
19. Hayes D Jr, Mansour HM, Kirkby S, Phillips AB. Rapid acute onset of bronchiolitis obliterans syndrome in a lung transplant recipient after respiratory syncytial virus infection. Transpl Infect Dis. 2012;14:548-550. [CrossRef]

20. Vu DL, Bridevaux PO, Aubert JD, Soccal PM, Kaiser L. Respiratory viruses in lung transplant recipients: a critical review and pooled analysis of clinical studies. Am J Transplant. 2011;11:1071-1078. [CrossRef]

21. Colom AJ, Teper AM. Post-infectious bronchiolitis obliterans. Pediatr Pulmonol. 2019;54:212-219. [CrossRef]

22. Zhang $\mathrm{L}$, Irion $\mathrm{K}, \mathrm{K}$ ozakewich $\mathrm{H}$, et al. Clinical course of postinfectious bronchiolitis obliterans. Pediatr Pulmonol. 2000;29(5):341-350. [CrossRef]

23. Lynch JP 3rd, Weigt SS, DerHovanessian A, Fishbein MC, Gutierrez A, Belperio JA. Obliterative (constrictive) bronchiolitis. Semin Respir Crit Care Med. 2012;33:509-532. [CrossRef]

24. Mauad T, Dolhnikoff M; São Paulo Bronchiolitis Obliterans Study Group. Histology of childhood bronchiolitis obliterans. Pediatr Pulmonol. 2002;33:466-474. [CrossRef]

25. Myers JL, Colby TV. Pathologic manifestations of bronchiolitis, constrictive bronchiolitis, cryptogenic organizing pneumonia, and diffuse panbronchiolitis. Clin Chest Med. 1993;14:611-622. [CrossRef]

26. Onay ZR, Ramasli Gursoy T, Aslan AT, et al. Postinfectious bronchiolitis obliterans masked by misdiagnosis as asthma. Pediatr Pulmonol. 2020;55:1007-1011. [CrossRef]

27. Jones KD, Urisman A. Histopathologic approach to the surgical lung biopsy in interstitial lung disease. Clin Chest Med. 2012;33:2740. [CrossRef]

28. Walia M, Goyal V, Jain P. Swyer-James-Macleod syndrome in a 10-year-old boy misdiagnosed as asthma. Indian J Pediatr. 2010 ;77:709.

29. Vieira Gde D, Yamagishi AY, Vieira NN, et al. Complication of postinfectious bronchiolitis obliterans (Swyer-James syndrome). Rev Assoc Med Bras (1992). 2015;61:404-406. [CrossRef]

30. Hochhegger B, Irion KL, Marchiori E, Bello R, Moreira J, Camargo JJ. Computed tomography findings of postoperative complications in lung transplantation. J Bras Pneumol. 2009;35:266-274. [CrossRef]

31. Eber $C D$, Stark $P$, Bertozzi $P$. Bronchiolitis obliterans on highresolution CT: a pattern of mosaic oligemia. J Comput Assist Tomogr. 1993;17:853-856. [CrossRef]

32. Leung AN, Fisher $\mathrm{K}$, Valentine $\mathrm{V}$, et al. Bronchiolitis obliterans after lung transplantation: detection using expiratory HRCT. Chest. 1998;113:365-370. [CrossRef]

33. Chen DH, Lin YN, Lan SL et al. Clinical characteristics of bronchiolitis obliterans in pediatric patients. Zhonghua Er Ke Za Zhi. 2012;50:98-102. [CrossRef]

34. Padley SP, Adler BD, Hansell DM, Müller NL. Bronchiolitis obliterans: high resolution $\mathrm{CT}$ findings and correlation with pulmonary function tests. Clin Radiol. 1993;47:236-240. [CrossRef]

35. Yüksel H, Yilmaz O, Urk $V$, et al. Clinical significance of lung perfusion defects in children with post-infectious bronchiolitis obliterans. Tuberk Toraks. 2009;57:376-382. [CrossRef]

36. Xie $B Q$, Wang W, Zhang WQ, et al. Ventilation/perfusion scintigraphy in children with post-infectious bronchiolitis obliterans: a pilot study. PLoS One. 2014;9:e98381. [CrossRef]

37. Hoshino Y, Morrison KJ, Vanhoutte PM. Mechanisms of hypoxic vasoconstriction in the canine isolated pulmonary artery: role of endothelium and sodium pump. Am J Physiol. 1994;267:L120-L127. [CrossRef]

38. Cazzato S, Poletti V, Bernardi F, et al. Airway inflammation and lung function decline in childhood post-infectious bronchiolitis obliterans. Pediatr Pulmonol. 2008;43:381-390. [CrossRef]

39. Mattiello R, Sarria EE, Mallol J, et al. Post-infectious bronchiolitis obliterans: can CT scan findings at early age anticipate lung function?. Pediatr Pulmonol. 2010;45:315-319. [CrossRef]

40. Teper AM, Kofman CD, Maffey AF, Vidaurreta SM. Lung function in infants with chronic pulmonary disease after severe adenoviral illness. J Pediatr. 1999;134:730-733. [CrossRef]

41. Castro-Rodriguez JA, Daszenies C, Garcia M, Meyer R, Gonzales $\mathrm{R}$. Adenovirus pneumonia in infants and factors for developing bronchiolitis obliterans: a 5-year follow-up. Pediatr Pulmonol. 2006;41:947-953. [CrossRef]

42. Mattiello R, Sarria EE, Stein R, et al. Functional capacity assessment in children and adolescents with post-infectious bronchiolitis obliterans. J Pediatr (Rio J). 2008;84:337-343. [CrossRef]
43. Kim J, Kim MJ, Sol IS, et al. Quantitative CT and pulmonary function in children with post-infectious bronchiolitis obliterans. PLoS One. 2019;14:e0214647. [CrossRef]

44. Mattiello R, Mallol J, Fischer GB, Mocelin HT, Rueda B, Sarria EE. Pulmonary function in children and adolescents with postinfectious bronchiolitis obliterans. J Bras Pneumol. 2010;36:453-459. [CrossRef]

45. Wanger J, Clausen JL, Coates A, et al. Standardisation of the measurement of lung volumes. Eur Respir J. 2005;26:511-522. [CrossRef]

46. Pellegrino R, Viegi G, Brusasco V, et al. Interpretative strategies for lung function tests. Eur Respir J. 2005;26:948-968. [CrossRef]

47. Owens CM, Aurora P, Stanojevic S, et al. Lung Clearance Index and HRCT are complementary markers of lung abnormalities in young children with CF. Thorax. 2011;66:481-488. [CrossRef]

48. Kim YH, Shin HJ, Sol IS et al. Lung Clearance Index and Quantitative Computed Tomography of Post-Infectious Bronchiolitis Obliterans in Infants. Sci Rep. 2017;7:15128. [CrossRef]

49. Evans DJ, Schultz A, Verheggen M, Hall GL, Simpson SJ. Identifying pediatric lung disease: A comparison of forced oscillation technique outcomes. Pediatr Pulmonol. 2019;54:751758. [CrossRef]

50. Jang YY, Park HJ, Chung HL. Serum YKL-40 levels may help distinguish exacerbation of post-infectious bronchiolitis obliterans from acute bronchiolitis in young children. Eur $\mathrm{J}$ Pediatr. 2017;176:971-978. [CrossRef]

51. Giubergia V, Salim M, Fraga J, et al. Post-infectious bronchiolitis obliterans and mannose-binding lectin insufficiency in Argentinean children. Respirology. 2015;20:982-986. [CrossRef]

52. Jagasia MH, Greinix HT, Arora M, et al. National Institutes of Health Consensus Development Project on Criteria for Clinical Trials in Chronic Graft-versus-Host Disease: I. The 2014 Diagnosis and Staging Working Group report. Biol Blood Marrow Transplant. 2015;21:389-401.e1. [CrossRef]

53. Kavaliunaite E, Aurora P. Diagnosing and managing bronchiolitis obliterans in children. Expert Rev Respir Med. 2019;13:481-488. [CrossRef]

54. Lenney W, Boner AL, Bont L, et al. Medicines used in respiratory diseases only seen in children. Eur Respir J. 2009:34:531-551. [CrossRef]

55. Vega-Briceño LE, Zenteno AD. Clinical guide for diagnosis and care of children and adolescents with post-infectious bronchiolitis obliterans. Rev Chil Enf Resp. 2009;25:141-163. [CrossRef]

56. Rosewich M, Zissler UM, Kheiri T, et al. Airway inflammation in children and adolescents with bronchiolitis obliterans. Cytokine. 2015;73:156-162. [CrossRef]

57. Yüksel H, Yilmaz O, Urk V, et al. Clinical significance of lung perfusion defects in children with post-infectious bronchiolitis obliterans. Tuberk Toraks. 2009;57:376-382. [CrossRef]

58. Yalçin E, Doğru D, Haliloğlu M at al. Postinfectious bronchiolitis in children: Clinical and radiological profile and prognostic factors. Respiration. 2003;70:371-375. [CrossRef]

59. Williams KM, Cheng GS, Pusic I, et al. Fluticasone, Azithromycin, and Montelukast Treatment for New-Onset Bronchiolitis Obliterans Syndrome after Hematopoietic Cell Transplantation. Biol Blood Marrow Transplant. 2016;22:710-716. [CrossRef]

60. Verleden GM, Verleden SE, Vos R, et al. Montelukast for bronchiolitis obliterans syndrome after lung transplantation: a pilot study. Transpl Int. 2011;24:651-656. [CrossRef]

61. Vos R, Vanaudenaerde BM, Verleden SE, et al. Anti-inflammatory and immunomodulatory properties of azithromycin involved in treatment and prevention of chronic lung allograft rejection. Transplantation. 2012;94:101-109. [CrossRef]

62. Friedlander AL, Albert RK. Chronic macrolide therapy in inflammatory airways diseases. Chest. 2010;138:1202-1212. [CrossRef]

63. Kingah PL, Muma G, Soubani A. Azithromycin improves lung function in patients with post-lung transplant bronchiolitis obliterans syndrome: a meta-analysis. Clin Transplant. 2014;28:906-910. [CrossRef]

64. Corris PA, Ryan VA, Small T, et al. A randomised controlled trial of azithromycin therapy in bronchiolitis obliterans syndrome (BOS) post lung transplantation. Thorax. 2015;70:442-450. [CrossRef]

65. Silva Filho LV, Pinto LA, Stein RT. Use of macrolides in lung diseases: recent literature controversies. J Pediatr (Rio J). 2015;91:S52-S60. [CrossRef] 
66. Okunishi K, Peters-Golden M. Leukotrienes and airway inflammation. Biochim Biophys Acta. 2011;1810:1096-1102. [CrossRef]

67. Verleden GM, Verleden SE, Vos R, et al. Montelukast for bronchiolitis obliterans syndrome after lung transplantation: a pilot study. Transpl Int. 2011;24:651-656. [CrossRef]

68. Chen X, Shu JH, Huang Y, Long Z, Zhou XQ. Therapeutic effect of budesonide, montelukast and azithromycin on post-infectious bronchiolitis obliterans in children. Exp Ther Med. 2020;20:26492656. [CrossRef]

69. Norman BC, Jacobsohn DA, Williams KM, et al. Fluticasone, azithromycin and montelukast therapy in reducing corticosteroid exposure in bronchiolitis obliterans syndrome after allogeneic hematopoietic SCT: a case series of eight patients. Bone Marrow Transplant. 2011;46:1369-1373. [CrossRef]

70. Bevacqua BK. Pre-operative pulmonary evaluation in the patient with suspected respiratory disease. Indian J Anaesth. 2015;59:542-549. [CrossRef]

71. Aguerre V, Castaños C, Pena HG, Grenoville M, Murtagh P. Postinfectious bronchiolitis obliterans in children: clinical and pulmonary function findings. Pediatr Pulmonol. 2010;45:11801185. [CrossRef]

72. Zhang L, Irion $\mathrm{K}$, Kozakewich $\mathrm{H}$, et al. Clinical course of postinfectious bronchiolitis obliterans. Pediatr Pulmonol. 2000;29:341-350. [CrossRef]

73. Cazzato S, Poletti V, Bernardi F, et al. Airway inflammation and lung function decline in childhood post-infectious bronchiolitis obliterans. Pediatr Pulmonol. 2008;43:381-390. [CrossRef]

74. Adde FV, Alvarez AE, Barbisan BN, Guimarães BR. Recommendations for long-term home oxygen therapy in children and adolescents. J Pediatr (Rio J). 2013;89:6-17. [CrossRef]

75. Nathan SD, Shlobin OA, Ahmad S, et al. Pulmonary hypertension in patients with bronchiolitis obliterans syndrome listed for retransplantation. Am J Transplant. 2008;8:1506-1511. [CrossRef]

76. Pate $A$, Rotz $S$, Warren $M$, et al. Pulmonary hypertension associated with bronchiolitis obliterans after hematopoietic stem cell transplantation. Bone Marrow Transplant. 2016;51:310-312. [CrossRef]
77. Glanville AR, Baldwin JC, Burke CM, Theodore J, Robin ED. Obliterative bronchiolitis after heart-lung transplantation: apparent arrest by augmented immunosuppression. Ann Intern Med. 1987;107:300-304. [CrossRef]

78. Dusmet M, Maurer J, Winton T, Kesten S. Methotrexate can halt the progression of bronchiolitis obliterans syndrome in lung transplant recipients. J Heart Lung Transplant. 1996;15:948-954. [CrossRef]

79. Browne PV, Weisdorf DJ, DeFor T, et al. Response to thalidomide therapy in refractory chronic graft-versus-host disease. Bone Marrow Transplant. 2000;26:865-869. [CrossRef]

80. Stadler M, Ahlborn R, Kamal H, et al. Limited efficacy of imatinib in severe pulmonary chronic graft-versus-host disease. Blood. 2009;114:3718-3720. [CrossRef]

81. Busca A, Locatelli F, Marmont F, Ceretto C, Falda M. Recombinant human soluble tumor necrosis factor receptor fusion protein as treatment for steroid refractory graft-versus-host disease following allogeneic hematopoietic stem cell transplantation. Am J Hematol. 2007;82:45-52. [CrossRef]

82. Kim CK, Kim SW, Kim JS, et al. Bronchiolitis obliterans in the 1990s in Korea and the United States. Chest. 2001:120:11011106. [CrossRef]

83. Pekcan S, Gökturk B, Reisli I. Successful Therapy with intravenous gamma globulin in two children with postinfectious bronchiolitis obliterans. Pulmonol Respir Res. 2017;1:9-12. [CrossRef]

84. Rama JA, Fan LL, Faro A, et al. Lung transplantation for childhood diffuse lung disease. Pediatr Pulmonol. 2013;48:490-496. [CrossRef]

85. Colom AJ, Maffey A, Garcia Bournissen F, Teper A. Pulmonary function of a paediatric cohort of patients with postinfectious bronchiolitis obliterans. A long term follow-up. Thorax. 2015;70:169-174. [CrossRef]

86. King TEJ. Bronchiolitis. In Fishman AP(Ed.) Fishman's Pulmonary Diseases and Disorders. 2nd ed. New York: McGraw-Hill; 1998:825-847. 